\title{
THE SURGICAL TREATMENT OF MITRAL REGURGITATION
}

\author{
BY \\ J. R. BELCHER \\ From The London Chest, and the Middlesex Hospitals, London \\ Received December 30, 1963
}

The surgical treatment of mitral valve disease is now more than a quarter of a century old, and valvotomy for mitral stenosis has taken its place as one of the most valuable operations in the whole of surgery. The same cannot be said for the surgical treatment of mitral regurgitation: indeed, because of the complexity of the anatomy of the attachments of the mitral valve, it is unlikely that it ever will be. Nevertheless, because mitral regurgitation may be lethal many different operations have been devised during the past few years in an attempt to alleviate the condition.

This paper is concerned with 26 patients who had or were thought to have significant mitral regurgitation, all of whom underwent open-heart operations. An attempt has been made to answer the three questions that follow. (1) Has surgery anything to offer for mitral regurgitation? (2) If so, which patients should be operated on? (3) What operation should be done?

\section{Selection of Patients}

As the results of operation for mitral regurgitation were uncertain, it was at first thought wrong to operate on patients with a mild disability and the first 10 patients were gravely disabled. This method of selection was necessarily reflected in a high mortality. As experience grew, and as the short-term results in the survivors could be assessed, the indications for surgery were widened, so that the patients operated on more recently sometimes had only moderate disability, and the operative mortality fell. It is now thought right to consider operation in any patient with mitral regurgitation who has a disability of grade 2 or more.

Of the 26 patients, 7 were men and 19 were women. Their average age was 41 , ranging from 23 to 55 years. Their disability was assessed from the history and graded according to severity as follows: Grade 1, mild disability; Grade 2, usually too disabled to work; Grade 3, severely disabled and often a history of cardiac failure; Grade 4, virtually house-bound often with almost irreversible cardiac failure. There were no patients in Grade 1,6 patients in Grade 2,13 in Grade 3, and 7 in Grade 4.

The average cardiothoracic ratio was 60 per cent (range $48-75 \%$ ). All radiographs except one showed pulmonary venous congestion, and in 18 Kerley's lines were seen. In all except the acute traumatic cases there was obvious enlargement of the left atrium and in some this was extreme. Calcification either on screening or on the postero-anterior film was seen in 7 patients in each of whom it was confirmed at operation.

Six patients were in sinus rhythm and the remainder in atrial fibrillation. In all save 8 ( 2 with traumatic regurgitation and 2 with mitral stenosis) the electrocardiogram showed left ventricular hypertrophy, "moderate" in 10 and "severe" in 8.

All patients except two were catheterized before operation. The results are given in Table I. The average mean pressures both in the pulmonary artery and in the left atrium were high, being raised in all except one. The highest mean pulmonary arterial and left atrial pressures were found in the same patient, in whom a severe tear of the valve had occurred at valvotomy five years 
TABLE I

Findings at Cardiac Catheterization in 24 Patients with Mitral Regurgitation

\begin{tabular}{|c|c|c|c|c|}
\hline & & Average & Highest & Lowest \\
\hline $\begin{array}{l}\text { Mean pulmonary artery pressure }(\mathrm{mm} . \mathrm{Hg}) \\
\text { Mean left atrial pressure (mm. } \mathrm{Hg}) . .\end{array}$ & $\begin{array}{l}\cdots \\
\cdots \\
\cdots\end{array}$ & $\begin{array}{l}36 \\
23 \\
4 \cdot 2\end{array}$ & $\begin{array}{l}95 \\
50 \\
20\end{array}$ & $\begin{array}{r}15 \\
10 \\
1\end{array}$ \\
\hline
\end{tabular}

earlier. The lowest pressures also occurred in the same patient, but in her case the catheterization had taken place before a valvotomy at which a cusp had been torn and had had to be repaired as an emergency. In 5 patients the pulmonary vascular resistance was greater than 6 units. As will be seen later this had an important bearing on the operative risk.

The diagnosis rested on a number of factors. In every patient there was a systolic murmur at the apex, and a diastolic murmur or a third heart sound. In 12 dominant mitral regurgitation had been found, or created at a previous operation. This evidence coupled with the radiological, cardiographic, and catheter findings led to a correct diagnosis of mitral regurgitation in all except 2 where there was dominant mitral stenosis. In 4 there was associated aortic valve disease, and in one this was severe.

Type of Lesion. The lesions of the valves were classified into three types: traumatic regurgitation, dominant regurgitation, and pure regurgitation. In 5 patients the valve had been torn during a previous valvotomy, involving the postero-lateral cusp in 4 and the aortic cusp in 1 . In 15 patients classified as having dominant regurgitation there was partial adherence of one or of both commissures, but the valve orifice exceeded $6 \mathrm{~cm}$. in circumference, and severe regurgitation was present; this appears to be the commonest variety. In 7 of these there was calcification of the valve, and calcification was confined to this group. In 4 patients there was pure mitral regurgitation, due to rupture of a chorda in 2 , and to a perforation secondary to bacterial endocarditis in 1 ; in the fourth the cause was not apparent. The remaining 2 patients proved to have severe mitral stenosis, though dominant regurgitation had been found at cardiotomy seven years previously in one of them.

\section{Operative Procedure}

In each case, the approach was made through the anterior part of the fourth right intercostal space, and in most, the sternum was divided without opening the left pleura. After the establishment of the bypass, the valve was reached in all cases except one via a vertical incision in the left atrial wall in front of the pulmonary veins. In the remaining case, the valve was reached via the right atrium across the septum.

The type of mitral regurgitation was assessed and the commissures were sought. It was not always found possible to be certain where the valve edges were fused, and this was particularly true in those with traumatic regurgitation. In the early cases an attempt was made to open the commissures with a knife or with scissors, but this was found to be an uncertain and unreliable method, and the dilator used for transventricular valvotomy proved to be a much more effective instrument for accurate division of the commissures and for separation of the chordæ and the papillary muscles. In 4 of the 5 cases of traumatic regurgitation complete commissurotomy was not possible.

A repair of the valve was then attempted, the technique varying with the cause of the regurgitation. Where the valve had been torn at a previous valvotomy, mattress stitches secured over small "teflon" patches were used. In the case with a perforation of the aortic cusp following bacterial endocarditis, a "teflon" patch was sewn into the deficiency. Where there was a rupture of a chorda, the valve edge was folded and sewn by the method described by McGoon (1960). In the remaining cases, in 7 of which there was calcification, and in all of which there was tissue loss, an annuloplasty was done: this method was intended to narrow the atrio-ventricular ring even though it was often not enlarged, and thus allow the inadequate valve tissue to become adequate to close the valve orifice during ventricular systole. In 7 cases the method described by Kay, Nogueira, and Zimmerman (1960) was used in which a piece of "teflon" was sewn round the end of the postero-medial commissure. The purpose of the "teflon" was to hold the 


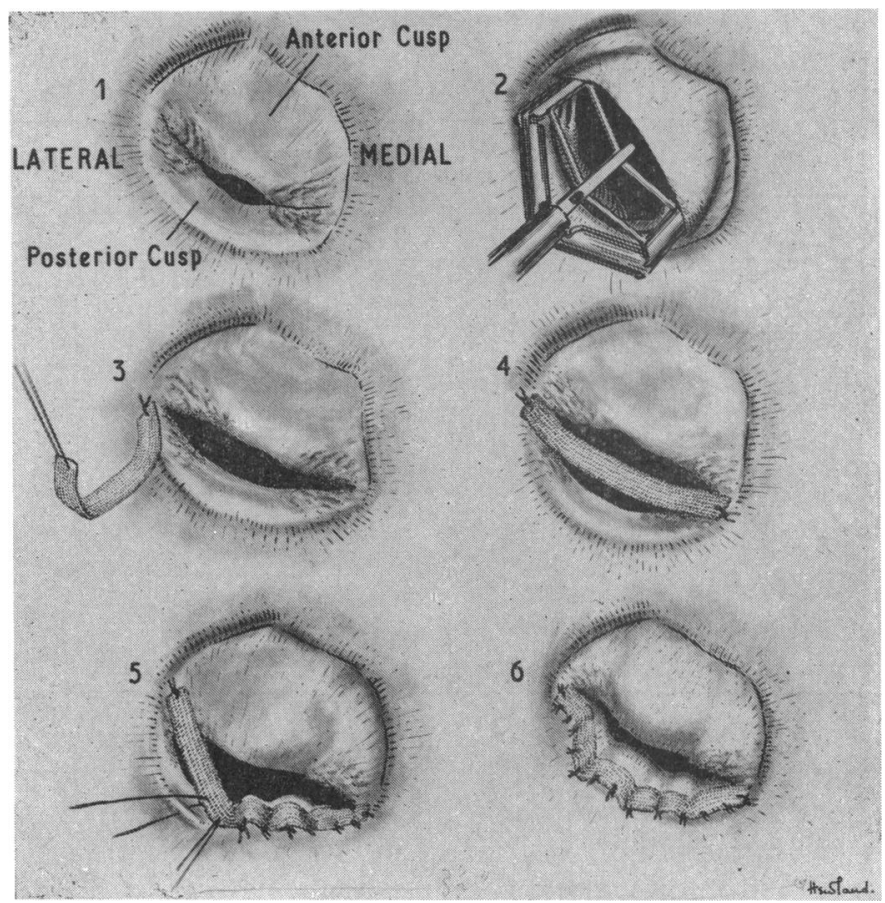

FIG. 1.-A diagram to illustrate the operation designed to shorten the annulus posteriorly. First the commissures are opened (2). A piece of "teflon" is then sewn to the end of the antero-lateral commissure (3), then to the end of the postero-medial commissure (4) and finally it is sewn to the posterior part of the annulus to shorten it and to push the posterior cusp forward (5) and (6).

stitches which extended over a length of more than $5 \mathrm{~cm}$. The ring was puckered and shortened and the "teflon" prevented the stitches cutting out.

In the last 11 cases, this method was modified. The "teflon" was sewn around the postero-lateral part of the ring from commissure to commissure. It was hoped that by this method, not only would the ring be narrowed, but the posterior cusp would be pushed forward to meet the edge of the aortic cusp. The "teflon" was first sewn to the end of one commissure, then to the other so that it stretched across the orifice of the valve. The centre was then sewn to the mid point of the posterior part of the atrio-ventricular ring, and two continuous sutures were used to complete the sewing to the ring (Fig. 1). In this way it was found easier to estimate the length of "teflon" that was required.

In the two patients with dominant stenosis the dilator was used, but in each case stitches had then to be put in to control small tears in the valve.

The assessment of the efficacy of the repair was found difficult as the retraction that was needed to expose the valve caused distortion of the ring and aggravated the regurgitation. Assessment of the size of the valve orifice was easier, and in some cases stitches had to be removed and replaced where too much narrowing had been caused by the repair. The left atrium was sutured round a vent which was not removed until the bypass had been stopped and the condition of the heart seemed satisfactory. In most of the severe cases, a tracheostomy was done at the end of the operation.

\section{RESULTS}

The first operation took place on May 29, 1960, and all were performed more than a year ago.

Mortality. Eight patients died at or very soon after operation, a mortality of 31 per cent,* and one more died of a pulmonary embolism in the fifth week after operation. Only 1 patient in the last 10 in the series died as a result of the operation.

* Since this survey a further 5 patients have been treated without fatality giving a mortality of 25 per cent. 
Comparison of the Murmurs, Left Atrial Pressures, and Radiological Appearances in 17 Patients with Mitral Regurgitation Before AND AFTER Repair of THE Mitral VAlVE

\begin{tabular}{|c|c|c|c|c|c|c|c|c|c|c|c|c|c|}
\hline \multirow{2}{*}{ Case } & \multicolumn{2}{|c|}{ Systolic murmur } & \multicolumn{2}{|c|}{ Diastolic murmur } & \multicolumn{2}{|c|}{$\begin{array}{c}\text { Left atrial } \\
\text { pressure (mm. Hg) }\end{array}$} & \multicolumn{2}{|c|}{$\begin{array}{c}\text { Pulmonary } \\
\text { vascular markings }\end{array}$} & \multicolumn{2}{|c|}{ Kerley's lines } & \multicolumn{2}{|c|}{$\begin{array}{c}\text { Cardiothoracic } \\
\text { ratio }\end{array}$} & \multirow{2}{*}{ Result } \\
\hline & Before & After & Before & After & Before & After & Before & After & Before & After & $\begin{array}{c}\text { Before } \\
(\%)\end{array}$ & After & \\
\hline $\begin{array}{r}1 \\
2 \\
4 \\
7 \\
9 \\
11 \\
12 \\
13\end{array}$ & $\begin{array}{l}4 / 4 \\
4 / 4 \\
3 / 4 \\
3 / 4 \\
3 / 4 \\
3 / 4 \\
3 / 4 \\
3 / 4\end{array}$ & $\begin{array}{l}\text { I.s.q. } \\
\text { Less } \\
\text { Less } \\
\text { I.s.q. } \\
\text { Less } \\
\text { I.s.q. } \\
\text { I.s.q. } \\
\text { Almost } \\
\text { none }\end{array}$ & $\begin{array}{l}1 / 4 \\
1 / 4 \\
1 / 4 \\
3 / 4 \\
1 / 4 \\
2 / 4 \\
2 / 4 \\
1 / 4\end{array}$ & $\begin{array}{l}\text { I.s.q. } \\
\text { I.s.q. } \\
\text { I.s.q. } \\
\text { I.s.q. } \\
\text { I.s.q. } \\
\text { Increased } \\
\text { Increased } \\
\text { None }\end{array}$ & $\begin{array}{l}- \\
\bar{Z} \\
22 \\
17 \\
20 \\
20 \\
30\end{array}$ & $\begin{array}{r}- \\
\bar{Z} \\
14 \\
14 \\
8 \\
15 \\
10\end{array}$ & $\begin{array}{l}4 / 4 \\
3 / 4 \\
2 / 4 \\
4 / 4 \\
2 / 4 \\
2 / 3 \\
1 / 4 \\
2 / 4\end{array}$ & $\begin{array}{l}\text { I.s.q. } \\
\text { Less } \\
\text { Less } \\
\text { I.s.q. } \\
\text { I.s.q. } \\
\text { Increased } \\
\text { Less } \\
\text { I.s.q. }\end{array}$ & $\begin{array}{c}2 / 3 \\
1 / 3 \\
3 / 3 \\
2 / 3 \\
\text { None } \\
-\end{array}$ & $\begin{array}{l}\text { Less } \\
\text { None } \\
\text { I.s.q. } \\
\text { I.s.q. } \\
2 / 3 \\
\quad \text { - }\end{array}$ & $\begin{array}{l}60 \\
70 \\
63 \\
74 \\
59 \\
52 \\
48 \\
60\end{array}$ & $\begin{array}{l}\text { Increased } \\
\text { Less } \\
\text { I.s.q. } \\
\text { I.s.q. } \\
\text { I.s.q. } \\
\text { Increased } \\
\text { Increased } \\
\text { I.s.q. }\end{array}$ & $\begin{array}{l}\text { Late death } \\
\text { Excellent } \\
\text { Good } \\
\text { Late death } \\
\text { Good } \\
\text { Late death } \\
\text { Good } \\
\text { Late death } \\
\text { (embolus) }\end{array}$ \\
\hline $\begin{array}{l}16 \\
18\end{array}$ & $\begin{array}{l}3 / 4 \\
3 / 4\end{array}$ & $\begin{array}{l}\text { Less } \\
\text { Almost }\end{array}$ & $\begin{array}{l}2 / 4 \\
2 / 4\end{array}$ & $\begin{array}{l}\text { Less } \\
\text { Almost }\end{array}$ & $\begin{array}{l}33 \\
16\end{array}$ & $\begin{array}{l}18 \\
20\end{array}$ & $\begin{array}{l}3 / 4 \\
3 / 4\end{array}$ & $\begin{array}{l}\text { Less } \\
\text { Less }\end{array}$ & $\begin{array}{l}3 / 3 \\
1 / 3\end{array}$ & $\begin{array}{l}\text { Less } \\
\text { None }\end{array}$ & $\begin{array}{l}71 \\
54\end{array}$ & $\begin{array}{l}\text { I.s.q. } \\
\text { Less }\end{array}$ & $\begin{array}{l}\text { Late death } \\
\text { Excellent }\end{array}$ \\
\hline $\begin{array}{l}20 \\
21 \\
22 \\
23 \\
24 \\
25 \\
26\end{array}$ & $\begin{array}{l}3 / 4 \\
3 / 4 \\
3 / 4 \\
4 / 4 \\
2 / 4 \\
2 / 4 \\
3 / 4\end{array}$ & $\begin{array}{l}\text { I.s.q. } \\
\text { I.s.q. } \\
\text { Less } \\
\text { Less } \\
\text { Less } \\
\text { I.s.q. } \\
\text { Less }\end{array}$ & $\begin{array}{l}1 / 4 \\
1 / 4 \\
2 / 4 \\
3 / 4 \\
2 / 4 \\
2 / 4 \\
2 / 4\end{array}$ & $\begin{array}{l}\text { I.s.q. } \\
\text { I.s.q. } \\
\text { Less } \\
\text { Less } \\
\text { I.s.q. } \\
\text { Less } \\
\text { Less }\end{array}$ & $\begin{array}{r}8 \\
17 \\
31 \\
24 \\
40 \\
44 \\
30\end{array}$ & $\begin{array}{l}10 \\
12 \\
28 \\
32 \\
28 \\
34 \\
40\end{array}$ & $\begin{array}{l}2 / 4 \\
2 / 4 \\
2 / 4 \\
1 / 3 \\
3 / 4 \\
2 / 4 \\
2 / 4\end{array}$ & $\begin{array}{l}\text { I.s.q. } \\
\text { Less } \\
\text { Less } \\
\text { I.s.q. } \\
\text { I.s.q. } \\
\text { I.s.q. } \\
\text { Less }\end{array}$ & $\begin{array}{l}2 / 3 \\
- \\
2 / 3 \\
3 / 3 \\
3 / 3 \\
3 / 3\end{array}$ & $\begin{array}{l}\text { Less } \\
\qquad- \\
\text { I.s.q. } \\
\text { I.s.q. } \\
\text { I.s.q. } \\
\text { None }\end{array}$ & $\begin{array}{l}63 \\
58 \\
66 \\
59 \\
71 \\
55 \\
62\end{array}$ & $\begin{array}{l}\text { Less } \\
\text { Less } \\
\text { I.s.q. } \\
\text { I.s.q. } \\
\text { Less } \\
\text { I.s.q. } \\
\text { I.s.q. }\end{array}$ & $\begin{array}{l}\text { Fair } \\
\text { Fair } \\
\text { Poor } \\
\text { Good } \\
\text { Good } \\
\text { Excellent } \\
\text { Good }\end{array}$ \\
\hline
\end{tabular}

The results in the survivors have been assessed on subjective, clinical, and radiological grounds. Post-operative catheterization was done in only one, but in others the pressure records taken at operation have been taken into account. Of the 17 survivors of the operation 5 have since died, 4 from cardiac failure, and 1 from a cerebral embolus occurring two years after a very successful operation.

The results in the 12 who are still alive are as follows: excellent, 3 ; good, 6 ; fair, 2 ; and no improvement, 1. The 3 patients with "excellent" results are leading normal lives; 2 are men who were previously unable to work and are now fully employed. The 6 with "good" results are much less dyspnœic than they were before operation; the only man in this group has returned to work, but all have some disability. Two patients in these groups developed cerebral emboli two months after operation; both are now recovering, but their exercise tolerance has been taken as that before the strokes occurred. The 2 patients with "fair" results are a little less disabled than they were before operation, and the one with no improvement had an immediate post-operative cerebral embolus making the exercise tolerance impossible to assess.

Alteration in Physical Signs. The intensity of the murmur produced by mitral regurgitation undoubtedly has some relation to the severity of the lesion; within broad limits this is also true of mitral stenosis. Thus the changes in these two physical signs might be expected to give an indication of the results of operation. These changes have been recorded in Table II where the changes in atrial pressure that were available are also recorded.

The systolic murmur was thought to have diminished in 10 of the 17 survivors. This coincided with subjective improvement in all except 2, 1 of whom had hemiplegia. Where the murmur was unchanged, the result was excellent or good in 2 patients. The diastolic murmur decreased in 7 , and coincided with a good result except in the 2 already mentioned. One patient in whom the murmur increased subsequently died, but there was no correlation with the results when the murmur was unchanged. When there was no change in either murmur there was almost always a bad result. Thus there was a close correlation between the heart murmurs after the operation and the subjective result.

Left Atrial Pressures. For technical reasons, pressure recordings before and after repair of the valve were made in only 14 of the 17 patients. The mean left atrial pressure seemed the most likely to give useful information (Table II). All except 3 showed a fall in left atrial pressure after the operation, and in some this was considerable (Fig. 2). The figures before repair corresponded 
reasonably closely with those obtained at catheterization although they were usually lower. The figures after operation were all obtained when the systemic blood pressure, and presumably the cardiac output, were low.

Radiological Changes. The radiograph taken just before the operation and the most recent one were compared (Table II). In 8 of the 17 patients the pulmonary vascular markings were noticeably reduced, in some greatly so (Fig. 3), and in 5 of these there was considerable subjective improvement. On the other hand there was no radiological change in 1 patient who improved greatly both subjectively and on catheterization. Among the patients who did not improve or who died subsequently, only 1 showed lessening of the vascular markings. Kerley's lines were visible

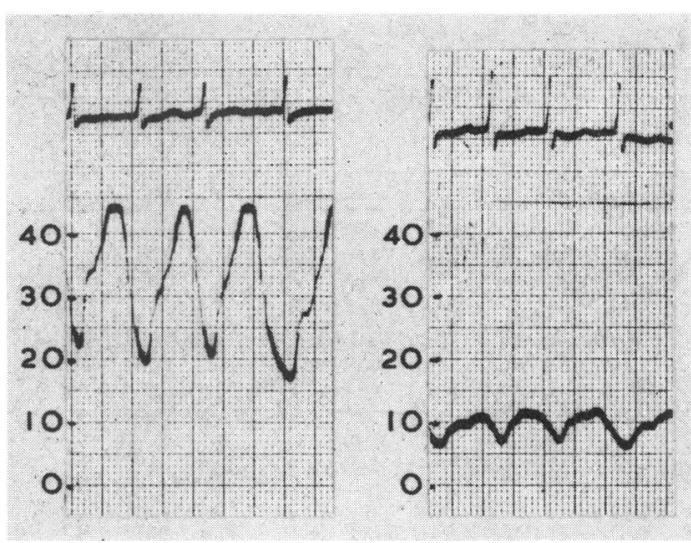

FIG. 2.-Left atrial pressure recordings taken at operation showing a considerable fall in pressure after annuloplasty. on the radiographs of 11 of the 17 patients before operation; in 2 (both with "good" results) the lines disappeared after operation, and in 3 (1 "good" result) they diminished.

The cardiothoracic ratio decreased (Fig. 3) in 5 patients and increased in 3, including 2 who died some months after operation. These changes usually correlated with the subjective findings, but where there was no change in heart size, there was no correlation with symptoms.

Thus the diminution of pulmonary vascular markings and of Kerley's lines correlated well with the subjective result; but although an increase in the cardiothoracic ratio coincided with a bad result (except in one case where a torn valve was repaired), a decrease was seen in only 4 of the 11 patients with considerable subjective improvement.

It appears, therefore, that the changes in the physical signs after operation correlate most closely with the subjective result; that where radiological changes have occurred, the correlation is good,

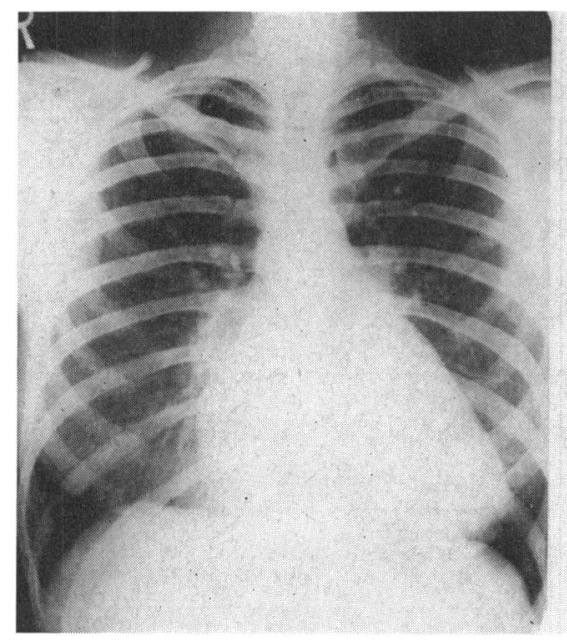

A

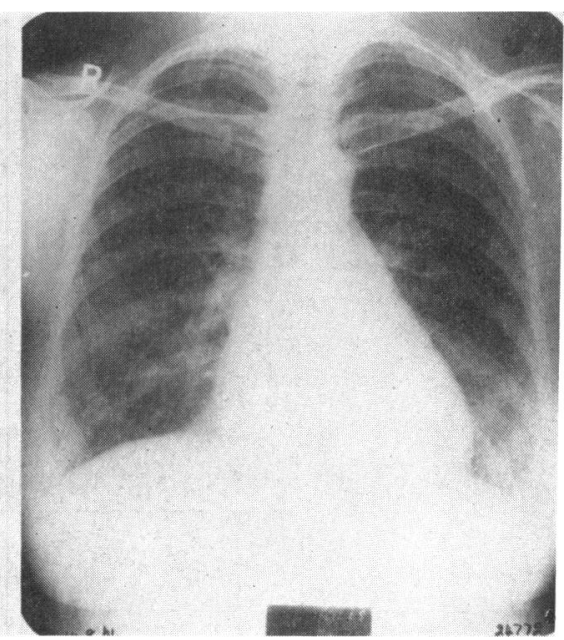

B

FIG. 3.-Radiographs taken (A) before and (B) after annuloplasty. They show a reduction of the cardiothoracic ratio and lessening of pulmonary venous congestion. 
TABLE III

Factors Influencing the Result of Mitral Valve Repair in 24 Patients

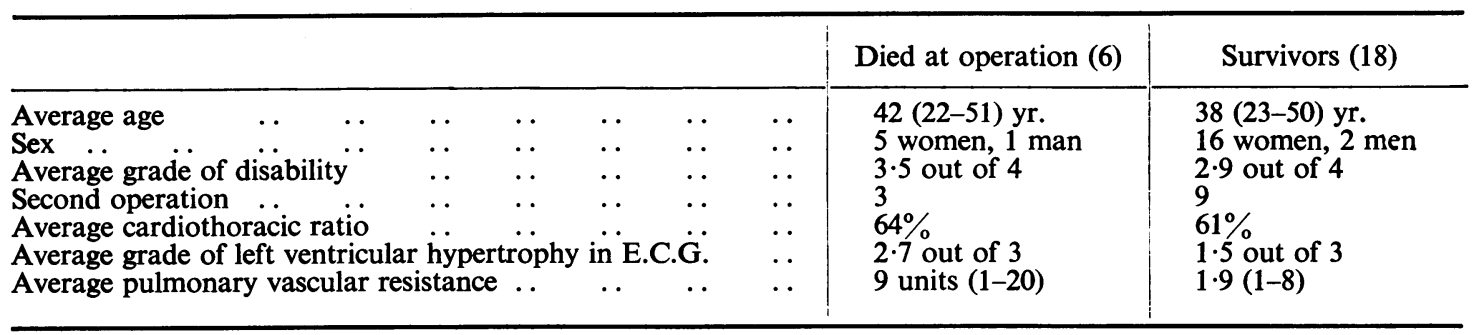

The two patients who died from a tracheostomy accident and cerebral embolism respectively have been excluded from this Table and from Tables IV and V.

but where they have not, it is poor; and that left atrial pressures taken at the end of the operation have little value in the prediction of the result.

Factors Influencing the Results. Various features were examined in the hope that indications and contraindications to the operation might be found. The operative details were also compared with the results to try to decide which factors were important and might lead to success. Two patients were left out of this analysis; of these, one died from an accident connected with tracheostomy and the other died from a cerebral embolus 14 days after operation; but until these occurrences, both were doing well. On the other hand, one patient who died two years after operation from a cerebral embolus has been classified by his status before he died. Although these three clearly have to be included in the assessment of mortality, it was thought right to consider them in this way when selection and operative technique were being discussed (Table III).

The pre-operative disability of those who died was, as might be expected, more than that of the survivors, but on the other hand a previous valvotomy did not increase the risk of the operation. It was found that the average cardiothoracic ratio was greater in the patients who died; yet the patient with the largest heart in the series survived, and the size of the heart appeared to have little influence on the results.

The only feature of importance in the electrocardiogram was the degree of left ventricular

TABLE IV

INFLuence of the TyPe of Lesion ON THE Results of Mitral Valve RePair

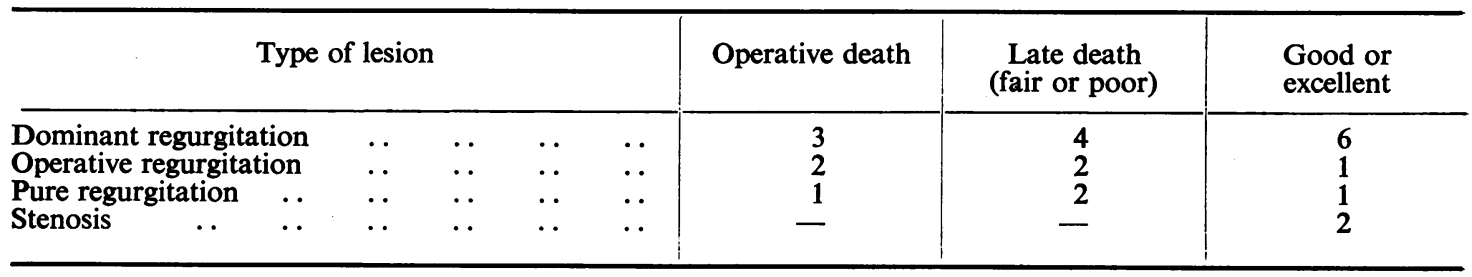

TABLE V

INFLUENCE OF THE Operative Factors on the Result of Mitral Valve RePair

\begin{tabular}{|c|c|c|c|c|c|c|c|c|}
\hline & & & & & & Operative death & $\begin{array}{l}\text { Late death } \\
\text { (fair or poor) }\end{array}$ & $\begin{array}{l}\text { Good or } \\
\text { excellent }\end{array}$ \\
\hline $\begin{array}{l}\text { Good commissurot } \\
\text { Fair or poor comm } \\
\text { Good repair } . . \\
\text { Fair or poor repair }\end{array}$ & $\begin{array}{l}\text { my } \\
\text { ssur } \\
\ldots \\
\cdots\end{array}$ & $\begin{array}{c}\ldots \\
\text { my } \\
\cdots\end{array}$ & $\begin{array}{l}\cdots \\
\cdots \\
\cdots\end{array}$ & $\begin{array}{l}\ddot{*} \\
\ddot{*} \\
\cdots\end{array}$ & $\begin{array}{l}\cdots \\
\cdots \\
\cdots\end{array}$ & $\begin{array}{l}3 \\
3 \\
2 \\
4\end{array}$ & $\begin{array}{l}5 \\
3 \\
3 \\
5\end{array}$ & $\begin{array}{l}9 \\
1 \\
5 \\
5\end{array}$ \\
\hline
\end{tabular}




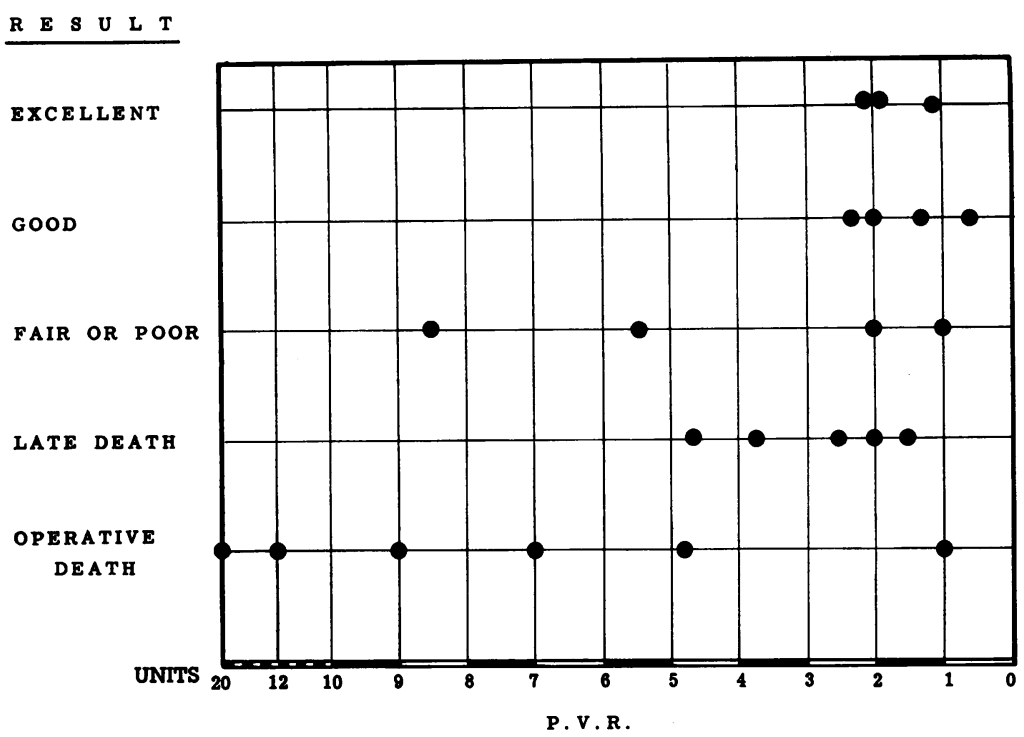

FIG. 4.-Mitral valve repair. The relation of the pulmonary vascular resistance (P.V.R.) to the result of the operation. Both the operative mortality and the final exercise tolerance appear to be worsened as the resistance increases.

hypertrophy. This was graded in each case from $0-3$, and it was found that the average amongst the survivors $(1 \cdot 5)$ was considerably lower than amongst those who died $(2 \cdot 7)$; but again, good and bad results were scattered throughout the range.

The most significant finding at catheterization was the pulmonary vascular resistance (Fig. 4). Only one patient with a resistance of more than 6 units survived (in her it was 8), but only two of the patients with a resistance of less than 6 units died, and one of these had severe aortic valve disease. The figures also suggest that the level of the vascular resistance may have some influence on the final exercise tolerance in the survivors, as all the excellent results were obtained in patients with a resistance of less than 3 units. This factor was thought to be by far the most important in its influence on the results.

The results in the three types of mitral regurgitation in the 24 patients under consideration are shown in Table IV. Only one of those with traumatic mitral regurgitation has done well, but in two others where a tear was made during the preliminary mobilization of the valve, the repair has led to good results. Of the 4 patients with pure regurgitation, 1 died at operation, 2 had fair results, and 1 had a good result until she had a cerebral embolus. Five good results have been achieved amongst the patients with dominant regurgitation, 4 of whom had calcification of the valve and in 1 this was severe. Both patients with dominant stenosis did well. Thus the type of the lesion, with the possible exception of the traumatic variety, had little influence on the result and calcification of the valve proved no bar to success.

Operative Data. An attempt was made to assess two factors in the operation itself, namely the completeness of the commissurotomy and of the mobilization of the chordæ tendineæ, and the efficacy of the repair (Table V). The first was easy to judge, the second was difficult. The importance of adequate mobilization of the commissures was clear in that only 1 patient who had an inadequate valvotomy had a good result. In only 1 of the cases of traumatic regurgitation was it found possible to achieve a complete division of the commissures; indeed their tight adherence may have been responsible for the tears, and the inadequacy of the valvotomy probably led to the poor results. The assessment of the repair appeared to bear little relation to the result, but the difficulty of making this assessment was probably responsible for this discrepancy. 
Discussion

When the surgical treatment of any condition is under consideration, it is essential to know what the outlook is without operation. There is little detailed information available about the prognosis of patients with mitral regurgitation. There are probably two reasons for this; first the repair of the valve has only recently been attempted, and secondly, accurate diagnosis of dominant mitral regurgitation is difficult, and without accurate diagnosis accurate prognostication is impossible.

Jhaveri et al. (1960), analysing 62 patients with mitral regurgitation diagnosed by clinical, radiological, and electrocardiographical methods, and another group in whom the lesion was found at necropsy, found that the disease ran a benign course. It was responsible for only 1.9 per cent of the deaths of patients dying from rheumatic heart disease. In this series however, 77 per cent had normal electrocardiograms. On the other hand, Wood (1956) estimated that the downhill course in patients with mitral regurgitation was faster than that in patients with mitral stenosis once symptoms had developed. Those with regurgitation took an average of 5.3 years to reach total incapacity whereas those with stenosis took $7 \cdot 3$ years. White (1951) supports this view.

Palpation of the regurgitant jet at operation is probably the most accurate method of assessing the severity of mitral regurgitation, and underestimation is unlikely. On this basis I have studied 38 patients operated on during the past 10 years, who had dominant regurgitation. Many of these were operated on before there was any possibility of repair of the valve in the hope that the diagnosis was erroneous or that mobilization of the valve would give some symptomatic improvement. The average length of history from the onset of symptoms until the time of operation was 3.9 years. Fifteen have had an operation for the relief of the regurgitation, the others were operated on before surgery for mitral regurgitation was available. Of the remaining 23, 12 are now dead, 3 more have such severe pulmonary hypertension that repair cannot be attempted, but 5 who had division of the adherent commissure despite dominant regurgitation have maintained some improvement. Those who died after the exploration of their valve, did so at an average time of 21 months after their operation and $4 \frac{1}{2}$ years after the onset of their symptoms. Thus 72 per cent have either died or have very advanced disease. These observations confirm the view that once a patient with dominant or pure mitral regurgitation develops symptoms, the downhill course is rapid. Some mortality is therefore acceptable when an effort is made to repair the leak.

Many operations for mitral regurgitation have been described. Blind procedures such as that of Glover and Davila (1957) in which the atrio-ventricular ring was narrowed by circumferential suture, or that of Harken et al. (1954) in which a baffle was sewn under the posterior cusp, were tried, but none proved successful. As soon as the cardiopulmonary bypass became available attempts were made to treat the regurgitation by direct means. Lillehei et al. (1958) used various types of prostheses partially to replace the shrunken valves, and Kay et al. (1958) devised a method for plication of the annulus. In principle these methods followed those of the blind techniques. More recently, after much experimental work excision of the valve and replacement with prostheses has been achieved by Starr and Edwards (1961) and by Ellis et al. (1963).

No one technique is likely to become established as the method of choice. There are two reasons for this: first the cause of the regurgitation varies from patient to patient, it being due to such different lesions as endocarditis, rupture of a chorda, or rheumatic destruction of the valve and its attachments, and secondly, because the mitral valve is a most complicated structure and when it has been damaged by disease its normal function is much more difficult to restore than when simple fusion of the commissures has caused stenosis. In this series some form of annular plication was used in most cases.

Before the advent of the bypass, it was suggested (Belcher, 1956) that commissurotomy alone might give some relief to patients with dominant mitral regurgitation, and in some cases where this was done prolonged improvement has been maintained. In this series the importance of mobilization of the valve has been reaffirmed. The adequacy of the mobilization appears to have had a considerable influence on the results, success having been achieved in only one patient in whom significant stenosis remained at the end of the operation. 
All those who have described operations for mitral regurgitation have stressed the importance of mobilization of the cusps and their attachments. Some (Lillehei et al., 1958) have recommended the opening of the commissures with scissors or with a knife. Others have found that division can be more consistently and accurately achieved by the use of a dilator (Merendino et al., 1959; Morris et al., 1962). In this series a dilator was used, as division of the commissures by sharp dissection was found to be unreliable.

The operative mortality in this series was 31 per cent. This is a high figure, but when advantage was taken of the lessons learnt in the early cases, and those with high pulmonary vascular resistance and gross aortic valve disease were excluded, the mortality fell sharply, and only 1 of the last 10 patients died. The mortality is comparable with that in other series (Table VI). All are high but the variation is probably due to the varying severity of the disease in the patients who were treated, as, in principle, all the procedures except that of Starr were some form of annuloplasty.

The influence of high pulmonary vascular resistance on the operative mortality has not been previously referred to, but it is suggested that even in the small number of cases described here, its malign influence is apparent. Only two deaths, excluding those due to accidents, occurred in patients who had a resistance of less than six units, and there was only one survivor with a resistance higher than this. One of the patients with a low resistance who died had severe aortic regurgitation; both Bigelow and Merendino have referred to the dangers of this association and both regard it as a contraindication to operation when it is severe.

In those series in which post-operative studies have been reported, diminution of the cardiothoracic ratio and lessening of the systolic murmur have been the rule. Merendino et al. (1961) found that the ratio had returned to normal in 9 of 11 patients and that pulmonary arterial pressure and stroke volume had improved in 6 . They also pointed out that the systolic murmur sometimes persisted despite normal catheter findings. Bigelow et al. (1961) also reported that all their surviving patients showed lessening of the cardiothoracic ratio and of the systolic murmur, and all had a fall in the left atrial pressure. These findings correlated with the subjective results.

Kay, Egerton, and Zubiate (1961), who have described the largest series of patients operated on for mitral regurgitation, have assessed them on subjective grounds and have correlated these findings with clinical, radiological, and cardiographic signs. About one-third of them were also catheterized after their operation: they report subjective improvement in 80 per cent of the survivors. The majority showed a reduction in the size of the heart although in some this took a long time to take place. Phonocardiograms showed a lessening of the systolic murmur in most, but this did not always correlate with the subjective result. Electrocardiograms showed little change although 70 per cent returned from atrial fibrillation to normal rhythm. In most, where catheterization was done, hæmodynamic improvement was seen and this always coincided with subjective improvement, although again it sometimes took months to appear. On the other hand, in some patients in whom there was a good subjective result there was little evidence of it at catheterization; this may have been because it was done too soon after operation.

In this series, where there was objective evidence of improvement there was almost always an increase in the exercise tolerance; on the other hand, deterioration of the objective findings coincided with a poor result. The closest correlation between the objective and the subjective findings was in the alteration in the physical signs. The radiological changes were not so consistent, and although there was almost always a fall in the left atrial pressure immediately after operation, the significance of this is uncertain.

From the published series (Table VI) it appears that at present the operation producing the best results is some form of annuloplasty, and that about three-quarters of the survivors have had considerable improvement. The figures presented here are similar. Although this operation may well be superseded in the future, it is doubtful whether the replacement of the valve by the various forms of prostheses that have so far been devised has yet done this. In the meanwhile, annuloplasty with adequate mobilization of the valve offers results good enough to justify its continuation.

Lastly, it has been stated by Kay, Mendelsohn, and Zimmerman (1961) that the extent of the $2 \mathrm{~N}$ 
TABLE VI

RePorted Results of Operations for Mitral Regurgitation

\begin{tabular}{|c|c|c|c|c|}
\hline Authors & & No. of cases & $\begin{array}{c}\text { Operative mortality } \\
\text { No. }(\%)\end{array}$ & $\begin{array}{c}\text { Percentage of survivors } \\
\text { improved }\end{array}$ \\
\hline $\begin{array}{l}\text { J. B. Kay et al. (1961) } \\
\text { Wooler et al. }(1962) \\
\text { Nichols } \text { et al. }(1961) \\
\text { Ellis } \text { et al. }(1963) \\
\text { Merendino et al. }(1961) \\
\text { Morris } \text { et al. }(1962) \\
\text { Bigelow et al. }(1961)\end{array}$ & $\begin{array}{l}\cdots \\
\cdots \\
\cdots \\
\ldots \\
\ldots \\
\ldots \\
\ldots \\
\ldots\end{array}$ & $\begin{array}{l}71 \\
48 \\
37 \\
32 \\
30 \\
24 \\
20 \\
12 \\
26\end{array}$ & $\begin{aligned} 20 & (28) \\
27 & (48) \\
7 & (19) \\
8 & (25) \\
13 & (43) \\
5 & (21) \\
5 & (25) \\
5 & (42) \\
8 & (31)\end{aligned}$ & $\begin{array}{r}80 \\
\overline{-} \\
70 \\
80 \\
90 \\
90 \\
100 \\
65\end{array}$ \\
\hline
\end{tabular}

improvement after the operation is inversely proportional to the degree of cardiopulmonary damage. If the pulmonary resistance is used to assess this damage, then the figures here confirm this statement, as nearly all the good results were obtained in patients with a low resistance, and broadly speaking, the lower the resistance, the better the result.

It may be concluded that in any patient with mitral regurgitation who has a disability of moderate severity early repair of the valve should be attempted. Secondly, an operation should not be attempted in patients with a high pulmonary vascular resistance or with severe aortic regurgitation (unless this is repaired at the same time), but that calcification of the valve is no contraindication to operation. It is suggested that if this policy is adopted, the operative mortality may be less than 20 per cent and that this is acceptable in view of the bad prognosis of the condition. Lastly, though there is no entirely satisfactory operation for all cases of mitral regurgitation at present, thorough mobilization of the valve combined with some form of annuloplasty will give improvement, which is sometimes dramatic, in a good proportion of cases.

\section{SUMMARY}

Repair of the mitral valve has been attempted in 26 patients with mitral regurgitation: 8 died at operation, 5 later, and of the remainder 10 have improved, some considerably.

The factors affecting the results have been considered, and a pulmonary vascular resistance exceeding 6 units has been shown to carry a high risk.

The operation in most cases was some form of annuloplasty, and a modification of Kay's method is described. The importance of adequate mobilization of the valve is emphasized, but calcification has not been found a contraindication to operation.

It is concluded that, with careful selection of patients, the operation should be recommended for those with mitral regurgitation as soon as disability develops.

\section{REFERENCES}

Belcher, J. R. (1956). The influence of mitral regurgitation on the results of mitral valvotomy. Lancet, $2,7$.

Bigelow, W. G., Kuypers, P. J., Heimbecker, R. O., and Gunton, R. W. (1961). Clinical assessment of the efficiency and durability of direct vision annuloplasty. Ann. Surg., 154, 320.

Ellis, F. H., M'Goon, D. C., Brandenberg, R. O., and Kirklin, J. W. (1963). Clinical experiences with total mitral valve replacement with prosthetic valves. J. thorac. cardiovasc. Surg., $46,483$.

Glover, R. P., and Davila, J. C. (1957). Surgical treatment of mitral insufficiency by total circumferential "pursestring" suture of the mitral ring. Circulation, 15, 661 .

Harken, D. E., Black, H., Ellis, L. B., and Dexter, L. (1954). The surgical correction of mitral insufficiency. J. thorac. Surg., 28, 604.

Jhaveri, S., Czoniczer, G., Reider, R. B., and Massell, B. F. (1960). Relatively benign "pure" mitral regurgitation of rheumatic origin. Circulation, 22, 39. 
Kay, E. B., Mendelsohn, D., and Zimmerman, H. A. (1961). Evaluation of the surgical correction of mitral regurgitation. Circulation, 23, 813.

-, Nogueira, C., Head, L. R., Coenen, J. P., and Zimmerman, H. A. (1958). Surgical treatment of mitral insufficiency. J. thorac. Surg., 36, 677.

,$- \frac{1}{568}$, and Zimmerman, H. A. (1960). Correction of mitral insufficiency under direct vision. Circulation, 21,

Kay, J. B., Egerton, W. S., and Zubiate, P. (1961). The surgical treatment of mitral insufficiency and combined mitral stenosis and insufficiency with use of the heart-lung machine. Surgery, 50, 67.

Lillehei, C. W., Gott, V. L., DeWall, R. A., and Varco, R. L. (1958). The surgical treatment of stenotic or regurgitant lesions of the mitral and aortic valves by direct vision utilizing a pump-oxygenator. J. thorac. Surg., 35, 154.

McGoon, D. C. (1960). Repair of mitral insufficiency due to ruptured chordæ tendineæ. J. thorac. Surg., 39, 357.

Merendino, K. A., Dillard, D. H., Bruce, R. A., Cobb, L. A., and Anderson, A. M. (1961). Experiences with the open correction of acquired mitral valvular disease, with special reference to insufficiency. Amer. J. Surg., 102, 280.

—, Thomas, G. I., Jesseph, J. E., Herron, P. W., Winterscheid, L. C., and Vetto, R. R. (1959). The open correction of rheumatic mitral regurgitation and/or stenosis. Ann. Surg., 150, 5.

Morris, J. D., Sloan, H., Wilson, W. S., and Brandt, R. L. (1962). An appraisal of clinical results in open mitral valvuloplasty. J. thorac. Surg., 43, 17.

Nichols, H. T., Blanco, G., Uricchio, J. F., and Likoff, W. (1961). Open-heart surgery for mitral regurgitation and stenosis. Arch. Surg., 82, 128.

Starr, A., and Edwards, M. L. (1961). Mitral replacement: Clinical experience with a ball-valve prosthesis. Ann. Surg., 154, 726.

White, P. D. (1951). Heart Disease, 4th ed. Macmillan, New York.

Wood, P. (1956). Diseases of the Heart and Circulation, 2nd ed. Eyre and Spottiswoode, London.

Wooler, G. H., Nixon, P. G. F., Grimshaw, V. A., and Watson, D. A. (1962). Experiences with the repair of the mitral valve in mitral incompetence. Thorax, 17, 49. 